\title{
The effect of CRM on employee performance in banking industry
}

\section{Lis M. Yapanto ${ }^{\text {a }}$, Ahyar Muhammad Diah ${ }^{\text {b* }}$, Kannapat Kankaew ${ }^{c}$, Anita Kusuma Dewi ${ }^{\text {, }}$ William Rene Dextre-Martinez ${ }^{e}$, Ardhariksa Zukhruf Kurniullah ${ }^{f}$ and Luis Augusto Villanueva-Benites ${ }^{g}$}

\author{
${ }^{a}$ Department of Water Resource Management, Faculty of Fisheries and Marine Science, State University of Gorontalo, Indonesia \\ ${ }^{b}$ Politeknik Negeri Samarinda, Indonesia \\ ${ }^{c}$ College of Hospitality Industry Management, Suan Sunandha Rajabhat University, Thailand \\ ${ }^{d}$ Politeknik Negeri Lampung, Lampung, Indonesia \\ eUniversidad Nacional Santiago Antúnez de Mayolo, Huaraz, Peru \\ ${ }^{f}$ Faculty of Communications Science, Universitas Mercu Buana, Jakarta Indonesia \\ ${ }^{g}$ Universidad Nacional Santiago Antúnez de Mayolo, Huaraz, Peru

\section{A B S T R A C T}

\begin{tabular}{l}
\hline C H R O N I C L E \\
\hline Article history: \\
Received November 6, 2020 \\
Received in revised format \\
January, 25, 2021 \\
Accepted March 82021 \\
Available online \\
March 8 2021 \\
\hline Keywords: \\
CRM \\
Customer retention \\
Technology \\
Alignment \\
Satisfaction
\end{tabular}

\begin{abstract}
The relationship between the organization and its clients is the life of every enterprise, whether it is a multinational corporation of several billion employees and a multi-million-deposit business or sole traders with a handful of daily customers. The relationship between the organization and its traditions is the key concern. Between these two cases, consumer relationship management $(\mathrm{CRM})$ is the same in theory and may differ significantly. Both the company and consumers have some factors to meet, such as the desires and expectations of all sides, before forming a contract. We need to earn a profit to succeed and to improve clients expect excellent support, better goods and reasonable pricing. The implementation of a CRM program will impact consumer service and customer knowledge for various purposes. Likewise, adopting a CRM strategy would definitely affect consumer loyalty and awareness. CRM guarantees that consumers are happy and strengthens ties between the company and its clients. Such practices improve the partnership between customers and sales representatives. The study carried out the quantitative approach in the delivery of the questionnaire to more than 100 bank customers. In concise and inferential statistics, the data were handled using the SPSS statistical method. Data indicates that the strong relationship between consumer loyalty and customer happiness of CRM technologies occurs and the stronger the overall customer satisfaction score, the larger the volume of CRM technology deployed.
\end{abstract}

\section{Introduction}

The basic justification for the life of a company is to satisfy clients ' expectations and through them regular patronage can pave the door to through productivity. Karamati et al. (2010) highlighted the value of consumer relationship management as a method to enhance better market results, representing an improvement in income, loyalty, increased quality and service delivery. In recent times, the interactions between companies and their customers have been questioned. Nonetheless, the consequence is that many businesses are badly associated with their customers, which can result in a lack of trust and a low income. Management of consumer interaction explores the entire phase through which a business covers all facets of what it does from vendors to final approvals and from internal employees to clients (Alessandro, Arbore Bruno, Busacca 2009). Like any organizational initiative, the ultimate objective of CRM is to increase profit. For CRM, this task is primarily accomplished by giving consumers a superior quality than rivals. Not only does CRM improve customer service, but also it reduces costs, waste and complaints, because of its good CRM capability. CRM also reduces stress on staff, as it reduces attrition, which is a significant cause of stress, as services and relationships improve. CRM also facilitates instant market research and it gives us a direct reaction to consumer relationships with our goods, services and results, even better than

\footnotetext{
* Corresponding author

E-mail address: ahyardiah27@gmail.com (A. M. Diah)

() 2021 by the authors; licensee Growing Science. doi: $10.5267 /$ j.uscm.2021.3.003
} 
any market analysis, by opening contact lines with your consumers. Good CRM also helps grow business and leads clients stay longer; customer churning reduces as new customers are referred to more satisfied clients; fire-fighting and problem shooting staff reduces demand, organization service flows are reduced and teams work more efficiently and happier (Becker et al., 2009). The happiness of the consumer is a significant CRM attribute, which cannot be circumvented. Indeed, customer satisfaction is central to successful application of the marketing concept. Most vision statements and strategic campaigns of organizations are intended to boost consumer loyalty (Blery \& Michalakopoulos, 2006). The idea of relationships is quite broad, since it applies to various fields, but it can be defined or represented as a distinct form, topics such as market interaction, consumer behavior, and customer experience management in terms of subject matter. To render specific facets of market interactions clear and observable (Blery \& Michalakopoulos, 2006), consumer experience management is targeted at providing a comprehensive and integrated understanding of client partnerships and the importance of market ties over time.

In the end, an improved CRM model supports both:

- Strategic research and development efforts of businesses,

- $\quad$ CRM concepts applying methods and strategies.

As a result of the effectiveness and intensity of the concept of CRM, customers would benefit from it through experiencing enhanced product delivery and organizations themselves would gain from it through increase in customer database, increase in performance and profitability.

\section{Statement of the Problem}

The key goal of a company is to satisfy consumers' expectations that contribute to improved productivity and demonstrates that market practices are useless without the presence of consumers. Companies sometimes neglect their consumer service and partnership and therefore shift much of their consumers ' purchasing preferences towards businesses that best represent them. The dilemma here is that the interest, treatment and consideration of clients go way beyond the price of the goods. Organizations also continue to do their hardest to maintain and even draw additional consumers.

Organizations at times are faced with the problems of

- Effectively targeting customers

- Developing strategy to achieve target behaviors.

- Behavior maintenance.

- Segmentation of customers based on customer profile and customer life-cycle stage.

Organizations have implemented different approaches and techniques to ensure they accomplish the following. The research seeks to determine the influence or effect on company efficiency of client relationship management and find out:

- To what extent does customer relationship management enhance a high level of performance in the organization?

- How does good customer service affect the level of productivity in an organization?

- What class of customer or classes of customers should enjoy the benefits of managing a customer relationship?

- What strategies should organizations take in seeking to achieve a successful and effective customer relationship?

- Should customer relationship management be included in the banking industry?

The objective of this study is to find out whether there is any link or relationship between customer relationship management and organizational performance. The specific objectives this study is aimed at are stated as below:

- To find out what propels customer loyalty,

- To bring out the distinction between customer relationship and organizational performance,

- To show that customer relationship management is a tool for acquiring high organizational performance,

- To determine the role customer service relation plays in every organization.

This research concentrated on the effects of the corporate success of customer relations management in the banking sector. A strong program of customer relations is critical and extremely important for all market organizations', but the main emphasis has been on the influence of customer relations in the banking sector in the light of these research projects. 
Various outsourcing market work on CRM has been performed in various areas such as Bank and financial services (Caruanas, \& Pitts, 2012), healthcare (Chahal \& Kumari, 2011), tourism and many travel divisions such as destination marketers. Essential performance drivers' technical changes and CRM engineering failures were central to CRM implementations (Ang \& Buttle, 2006) issues linked to obstacles. Many CRM studies included subjects such as CRM best practices (Coltman 2007), CRM philosophical frameworks and the CRM recommendations. Although most of the work was technical in nature, there is also a continuing increase of research on social CRM. Several scales were built to quantify various facets of CRM. Coltman (2007) established and validated a metric scale for the condition of CRM adaptation in financial companies utilizing measurements such as CRM, information management and technology-based CRM. Dimitriadis and Stevens (2008) explored the generalizability size and applied it to the banking and insurance industries. They established a scale for the analysis of CRM capabilities based on the services industry in general: consumer engagement efficiency, customer relationship performance enhancement, and customer recovery capability.

A calculation framework to explain the CRM method has been built based on a broad range of business sectors. (Stevens et al., 2008) and comprises seven specific systems, including, targeting management, consumer experience management, product / service configuration, extension management. During the three phases: introduction, repair and termination in conjunction with various financial services firms, lodging, online store, and power resources, they checked the CRM mechanism implementation. Zikmund (2000) looked at backstage CRM, which requires execution, in a similar manner to the other dimensions in CRM. Evidence suggests that CRM practices in the front stage involving customer behaviors across numerous interactions have not experienced a systematic development process. From the point made by Zablah et al. (2004) regarding the low emphasis on research that measures CRM 's success from a consumer viewpoint, the value of front-stage CRM can also be established. CRM is supposed to provide the companies with various benefits, according to the literature. The advantages of the CRM theory itself and the disadvantages of CRM structures can be separated into two large classes. In the fields of consumer recruitment, customer growth, maintenance of clients, business creation, and client equity increase are the advantages of CRM. Richards and Jones (2008) identified seven key benefits of CRM systems: enhanced customeroriented focus, improved channel-wide preferential service offering, improved sales force efficiency and efficiency, personalized marketing messages, personalized products and services, increased customer service efficiency, and efficiency and improved pricing. Although the CRM philosophy offers broad advantages, much of the advantage of CRM is discussed on the basis of the implementation of a particular system of CRM (Winer, 2001). The organization has not been studying much into the benefits gained from the cumulative CRM experience. There are various tests of the performance of CRM applications. Winer (2001) used the customer interest assessing method in the banking sector. He assessed CRM performance across the company's image and level of service in the hotel industry. He proposed a holistic method that the outcomes of CRM be calculated using the measurements of asset worth, company asset and partnership equity (Bligh, 2004).

While researchers regularly point out that CRM produces loyalty, only a few studies analyze the impact of CRM on loyalty. The value of CRM is further simplified by emphasizing its consumer benefits. There has been wide-ranging discussion of non-financial relational benefits, including confidence benefits, social benefits and special care benefits. The advantages of trust include learning what to expect from service sessions, decrease in distress and faith in the planned operation. The advantages include informal recognition of social security programs (Bligh, 2004). The preferential preference advantages include premium cuts, smoother and supplementary facilities. He said that trust advantages are the most effective. Given the aforementioned benefits for the partnership dyad parties [the company and the customer, the advantages listed previously were highly discussed for both parties. Several researchers suggested the CRM findings in firm efficiency were optimistic. It is also observed that CRM is an immense expense with no incentive and no verification of success. In fact, academics have raised reservations about their empirical proofs. Many tests have shown that CRM structures have been crashing. In the evaluation of many Rigby et al. systems (2002), 55\% were unsuccessful. In addition to researchers, large industry analysis companies, including Gartner and Mckinsey, have released a variety of papers on CRM deployment performance and failure rates. However, many of the debates on CRM loss are regarding not only the theory itself but also CRM apps. Consumer questions over the quality of partnership building activities have been identified. Danaher et al. (2008) studied the value of partnership transfers in three kinds of business organizations: telecommunications providers, banks, physicians, and analyzed customers' desire to participate in relationships. When contrasting with the other two services markets, they find that consumers are more involved when connections with physicians. This showed that customers are more willing to maintain long-term relations when the service provider is viewed as an authority, social ties with the company and frequent interactions with the service provider are important to the nature of the service. Verhoef (2003) rationalized the customer's reluctance to stick with a single company because of fears over missing options and the need for something different. Therefore, although some consumers would choose to establish a long-lasting partnership with certain company organizations, some may opt differently purposefully, based on the business background. It is therefore necessary to evaluate consumer aim for introduction of relationships before approaching customers. Johnston (2004) defined relationship initiation as "an intention of a customer to build a relationship with a firm while buying a product or service attributed to a firm, a brand, and a channel" Accordingly, the lack of customer interest in initiating relationships is referred to as a transactional intention. 
Several reasons led to CRM use in hotels. Amongst them is the homogenous nature of the hotel sector and the need to distinguish its central offering from its rival. Although the value of CRM adoption has been emphasized by globalization and consequently international pressure, certain factors, like IT technology changes, have been helpful in successful CRM implementation. This makes CRM important and convenient to adopt environmental conditions. The hotel industry is a reliable industry for information. All hotels and their guests have been affected by the quality of knowledge. Customer information plays an extremely important role in the practice of CRM from the hotel point of view. However, customeroriented exposure to a broad range of user-generated contents has posed several obstacles for hotels (Jhonston, 2004). Although consumers have no limitations on details, this provides travelers with a wider option. It makes things simpler and enticing for travelers to turn. As a consequence, consumer attrition and rising acquisition costs are encountered in hotels. The adverse effects in such a context were recommended to be overcome by CRM. In the practice of CRM in the hotel context, information technology (IT) has played a vital role. Several researches addressed how IT capability could be used in CRM deployments and how to develop electronic interaction management systems. The key function that hotel websites play in developing consumer ties was noted by Venetis and Ghauri. (2004). The major effect of CRM activities and Internet use on consumer service and loyalty, on interaction and on establishing and sustaining quality ties with consumers has been described by Ghauri (2004). He addressed how the IT facilitates the gathering of details at different points of concern, such as bookings, check-in, check-out meetings and on-site stays. It helps hoteliers, according to hotel tastes, to customize unique guest packages, facilities and promotions. CRM analysis in the hotel setting, close to conventional study, focuses largely on issues relevant to deployment. This propensity to concentrate on the application of CRM tends to be warranted in the context of the poor performance of CRM implementations in the hotel sector. The CRM work based on applications enhanced (Sarmaniotis et al., 2013). Various steps were taken to assess the impact of CRM in the hotel sense. It includes loyalty, (Dwyer \& Tanner, 2005), business success, partnership consistency, \& client life-time value (CLV). It includes loyalty, business performance. CRM success assessment is primarily focused on CRM which analyzed the context aspects of CRM instead of the customer's experience. Consequently, the CRM efficiency assessment activities of hotel clients have been restricted to the maximum standards. In the hotel context, the researchers have listed numerous customer-orientated CRM practices. Farquhar (2004) for example suggests that CRM was historically applied easily, such as consumer knowledge, client interaction, conversational habits and organizational skills. With the wide usage of technology, current CRM serving consumers has common activities such as staying in touch with clients continuously, direct texts, flyer miles or coupons on certain items, exclusive offers, due acknowledgement calling the consumer by email, rewards services, blogs and tailored mails, and to consumers. Given the multiple CRM activities in the hotel industry, many approaches remain restricted by observational studies with the exception of the reward schemes (Ghavami \& Olyaei, 2006). CRM has a positive effect on the efficiency of partnership, while partnership consistency has a positive impact on the importance of consumer existence. The effect of connection efficiency on consumer satisfaction was calculated by a survey of hotel guests in Taiwan on the basis of consumer-faced CRM activities in the hotel industry (Ghavami \& Olyaei, 2006).

The CRM's causal link to the effects has been defined by partnership consistency by both Gifford (2002) whereas the confidence and loyalty by Greenberg (2004) have been established. In fact, a mixture of mental and disposition variables assessed the efficacy of CRM. These three reports analyzed tourists to a particular location. The participants were also a combination of individuals who worked both for pleasure and company. In contrast to the above studies which sampled a combination of business and leisure travelers to a particular destination, this study investigates the impact of CRM exclusively in the leisure travel market. Since this research aims to examine choices of hotels at a foreign location in general, this analysis was not restricted to a single country or hotel. There are directly determined relationships between CRM and its outcomes. The outcomes of CRM were measured based on behavioral loyalty - repeat visitation and word-of-mouth. A need to understand the direct impact of CRM upon repeat visits and words of mouth is the reason for choosing behavioral loyalty. Its approach will produce a detailed customer-facing appraisal of CRM.

\subsection{Loyalty programs as a customer relationship management (CRM) practice}

CRM's reward services are a crucial case. According to Greve (2006), consumer growth, market engagement and customer maintenance are basically CRM's rewards services. According to Becker et al. (2009), a repeated buying and engagement of the consumer is an essential consequence of reward initiatives through creating strong partnerships. Loyalist schemes, because they are perceived to be less price-sensitive, expend a lot of time and promote constructive WOM, have often proven successful because of the decreased costs of servicing loyal clients. This is evidently valid in the hotel sector, as well as in other associated sectors such as aeronautical firms, hotels, shopping and merchandising (Becker et al., 2009). Several researchers have observed a proliferation of reward schemes. Lewis (2004) indicated that travel related sectors such as aviations, hotels and rental cars are especially successful in reward programs. First in the aviation market, with the launch of a flyer frequency system in 1981, reward schemes started in the hospitality and tourism industry. In the hotel sector also, loyalty programs were becoming considerably popular. The Holiday Inn and the Marriott first implemented rewards schemes in the hotel industry in 1984, and the writers refer to them as 'homecoming services' or 'homecoming initiatives.' Already rewards programs, both at large and in small hotels, have grown into an integral hotel policy (Guo et al., 2008). The introduction of hotel reward schemes can be explained by helping to resolve pressure and boost market share. In addition, consumers were encouraged to purchase again and to chart their usage habits. Hair et al. (2007) reported an 
increase in occupancy and competitiveness in the hotel market rewards programs. In the luxury business field, rewards schemes are increasingly common in contrast to the general segment (Guo et al., 2009). The study found out that reward programs are more common among enterprise and high-income travelers. The study looked at business context to look at differences in loyalty programs between members and non-members. It was observed that participants of the reward system were willing to pay higher prices than non-members. Skogland and Siguaw (2004) also acknowledged the inability of rewards programs in trying to deliver the expected benefits given the value added to loyalty programs in the hospitality field (McCall \& Voorhees, 2010). DeKay (2009) identified the principal reason for the lack of loyalty in the recreational area as less frequent journeys and fewer redemption opportunities in comparison to travelers. The financial advantages of reward services tend to be unclear, primarily because management metrics to assess them are not appropriate. Juan and Yan (2009) also reaffirmed the value of engaging in alternate CRM action. The claims further highlight the previously mentioned value of customer-facing observational work on CRM activities.

\subsection{Other loyalty generating stimuli in the hotel context}

Beyond CRM, several other triggers for replicated and word-of - mouth generation have been addressed. We also provide standards of operation and hospitality (Kandampully \& Hu, 2007). While the predicted effects are the same, the boundaries between them and CRM remain very unclear. Where human resources are one of CRM's core components, however, the concepts of hospitality clients' services and service quality (Keramati et al., 2010) were also found to have been one of the key concepts. A mixture of complete quality management (TQM) and Complete CRM is a direct association between CRM and price. Level of relation has been one of the main measurements of standard of service assessment. Keramati et al. (2010) across dimensions like relative interest at location, amenities and timeliness conceptualized the partnership standard in hotel services setting. Chen and Chen (2014), by a mixture of CRM and non-CRM measurements, conceptualized the consistency of relationship: efficient and severe operation, equipment functional, health and climate.

Many of them will not explicitly impact organisations' CRM activities. As described in early parts in the study (Keramati et al., 2008) conducted main practices concerning the application of CRM: creation of a core service, the improvement of the partnership with specific clients, the enhancement of the core service by extra benefits. It is evident from Berry that other measurements, which cannot be linked to the organization's CRM activities often, are essential to the growth of consumer relationships. CRM is commonly called loyalty-building practice. Nonetheless, all of the other factors such as the standard of service is mostly addressed through observational explanations on loyalty management methods rather than CRM. As a result, the importance of the CRM aspects to loyalty production was not sufficiently understood by the CRM community. It implies that the area of CRM activities needs to be identified. CRM is defined as all CRM-related practices in this study "three buy-time zones, pre-countering, interaction and post-encounter," which have the effect of contributing to the field of CRM.

\subsection{CRM and Customers}

CRM is significant, because it gives an organisation's multiple marketing advantages that daily data collection surveys are no longer required, because CRM is a continuous operation. This can be done by purchasing and consuming activity, as well as experience, any time they purchase and transact (Keramati et al., 2008). CRM also makes an enterprise really competitive. At first a consumer may be over marginal profits, but after a period of time, consumers can become competitive. It ensures that the company will begin to reap its rewards. It is also really important to improve revenue and market share because it provides more incentives and brand equity for the development of a customer's franchise. CRM helps other companies, as it has a beneficial impact on the consumers, who are switching to its technologies.

\subsection{Customer satisfaction}

There is no doubt about the value of consumer loyalty. Holding consumers is much better than getting fresh ones. Therefore, it is important for a company to ensure that an entity keeps its customers. That's what makes a business important for consumer service. This is described as a marketing concept that allows one to recognize whether an organization's goods or services match or surpass consumer standards. This can be defined in the time period for the product or service as satisfying consumer desires, demands and wishes. Customer loyalty is vital as it lets business owners and executives' control and develop their organizations. Another downside is that consumer loyalty is found in a dynamic market environment in which companies will contend for consumers. This is important that the survey projects thoroughly concentrate on customercritical problems (Lawson-Body \& Limayem, 2017). Consumer satisfaction provides a great deal of benefits from helping to recognize incentives open for service and product improvement, to appraisal and compensation schemes. It can also be described as a consumer's quantification of his / her feelings about the perceptions of a commodity, whether it is gratification or frustration. The consumer's reaction to and appraisal of the presumed difference between prior expectation and the actual product experience following consumption is complied with. That generally implies that consumer loyalty is accomplished if services are offered that exceed customer standards if services are less than anticipated. 
The satisfaction of customers is often described as an assertion that customer interaction was as wonderful as it should have been. Satisfaction is not merely a response but rather an emotional reaction to the perceptions of individual goods or services that are purchased, retail stores or also molar activity trends such as browsing and purchasing preferences and the general marketplace. The psychological state arising from unclear intentions and from user emotions regarding a purchasing environment is another concept of customer satisfaction (Levesque \& McDougall, 1996).

\subsection{Relationship between Service Quality Attributes and Customer Satisfaction}

Quality of service and the interaction between consumers have a relationship that is very transparent and based on quality perception and consumer loyalty. One persistent concern is whether a partnership can be challenged as regards consumer loyalty and service efficiency. Because of the lack of knowledge of consumer expectations and resources, most quality designs crash. Effective service efficiency characteristics will only have beneficial consequences. Tangible, consistent, assurance, receptiveness and empathy are the standard of service qualities that result in consumer loyalty. Tangible facilities such as technologies and utilities can please consumers while talking about tangible and consumer loyalty, whereas customer satisfaction is diminished by the lack and/ or bad tangible facilities. Secondly, as we understand continuity and consumer delivery, the most significant characteristic of customer loyalty in terms of service efficiency might be, for example, telecommunications reliability. Thirdly, the strong partnership between insurers and consumer loyalty is clear. It is a positive one. Finally, the connection is favorable in terms of reactivity and consumer loyalty, as long as the service provider reacts to the customer helpfully and swiftly. Customers' references and ads are an important way to get new customers because the first-time quality is not required (Herman \& Renz, 2008).

\subsection{Customer acquisition}

The first task in the control of our consumer existence is the retention of consumers. This applies to modern customers' strategies. As a boss, that is also the first thing they do while attempting to create a valuable base for customers. Acquisition normally includes three main choices, regarding the candidates, how contact will be treated and the deals will be given to them. It is described as a process for the identification, approach and creation of new ties with customers. The preference of viewpoints with the best potential to become strategically valuable clients is quite important when an acquisition is about to be carried out. In order to select the most lucrative and trusted potential clients, it is the acquisition of the right consumer that is the first phase in customer experience management. The condition in which a business finds itself influences the value of the client acquisition. An existing business would not be as involved in purchasing a new company, hence it relates so much to where a company stands. In consumer acquisition, a variety of problems are of interest. Include them;

- How to purchase consumers at a discounted price

- Need for appealing user integration

- More consumers are purchased.

- More appealing consumer acquisition

- Acquisition of alternative platforms to consumers.

In order to consider the importance of the consumer, the current acquisition price for the customer has to be calculated within the company's main channel and cost difference within each client category has to be determined. Customer buying is the main activity for handling the customer existence as customer retention without customer retention as a predecessor will be futile and needless. Customers' value in an organization is undeniable. Both firms will concentrate on attracting consumers as a new product is launched. There's everything about modern startups. It is really necessary that start-up firms, who are eager to expand and rely very much on the acquisition of consumers. The amount of control a single client in a company may have is unquestionable. One consumer addition may trigger more potential consumers; one customer's failure may have catastrophic implications for a company (Mooney et al., 1996). Customer retention often involves the existence of a normal attrition. Objectives, platforms and deals often shape the foundation of questions about an acquisition strategy.

To establish an appropriate procurement plan;

- A business would recognize the targets for potential clients.

- The process of methodology used to procure these goods

- The deals that they intend to produce.

If a company resources a client acquisition strategy, it is really necessary to make transparent the discrepancies between an acquisition plan as opposed to the retention plan. It is also important to note that the two proposals are very distinct when they are sponsored together. The two plans are also linked. 


\subsection{Customer Retention}

As mentioned previously, consumer retention is better than new customers (Newell 2000). It is therefore a very significant management issue, especially when an entity experiences competition from other companies or low acquisition of new customers. It is so important that it can't be overlooked and it is really important for an organisation's existence. Customer retention in connection marketing is the reason for the potential to have superior economic ties. The mechanism through which marketing plans and activities of a company are aimed at current consumers can be used to describe consumer acquisitions. It is evident from this that the development of long-term consumer relation and customer loyalty for a company is essential. It would not be possible to rely on retention if there was little consumer loyalty. In order to truly appreciate the value of maintaining consumers, companies must realize the economics and financial implications of consumer retention in their enterprises. One inference that is probable is that success will still be reached for the retention of customers. Customer maintenance in CRM is of undeniable significance. The loyalty of consumers is highly valuable since loyal customers build a long-term partnership with the business, often prioritize their services or items and willingly educate all interested customers on services and products from the organisation. As long as a business has a better reputation for gods or resources, consumers can still give you preference. Quality is important because it is advantageous for the business to make customers understand and see value. Organizations invest a lot of time and care on attracting potential clients, while seeing the advantages of continuing to maintain the consumers they currently have and making sure they are absolutely content to prevent sacrificing them. Often companies get concentrated and may not realize what is necessary. The creation of longterm consumer partnerships is more advantageous than the emphasis on revenue. With respect to our case studies CMWU, the company must guarantee that consumers pay the water bills when appropriate which is a continuing procedure in order to ensure the customer's retention in the CRM. Consumer retention is certainly pursued if CMWU maintains constant customer loyalty. The only challenge is the viability of CMWU, which is unlikely.

This is how they control their consumers' retention and because buyers can't demand improvements or increase significantly as long as they are happy. New consumers must be gained in order to reach some sustainability.

\section{Factors that affect CRM successful implementation}

To establish partnership management principles effectively, assumptions and values must be called into doubt. Good internal alliances around the CRM plan are other influences supporting the effectiveness of CRM. If a company will establish good internal relationships around CRM, the application is bound to succeed. It is therefore critical for the effectiveness of the CRM framework that the workers gather data correctly. This will only be achieved if the workers are conscious of what they can do and how they should do it.

\subsection{Sample Selection}

The ideal solution is for a researcher to get the data from all the employees. It is, however, nearly impossible; thus, a small subset of the population is drawn which should be representative of all its members. The sample population in this study was limited to employees in banks. In order to administer the questionnaires of the same incentives, we used the basic random sample to pick the respondents of the fund.

\subsection{Sample size}

In any research, it is very important to determine an efficient sample size. Too little samples can lead to poor results, whereas too large samples can waste time and resources. The investigator used a sample of 60 with 10 staff and 30 bank customers. The 10 workers of the division of the Bank touch customers directly. Even choosing 50 respondents from the Bank's consumer base, per fifth to arrive at the branch, picked them.

\subsection{Data type and collection procedures}

The researchers clarified various methods used to gather data such that this analysis was appropriate. The quantitative and qualitative data was included in this analysis. In different branches of Banks, researchers used the following data collection methods, including documentation analysis, to acquire results. The researcher then gave the interviewees questionnaires collected through deliberate researcher sampling methods. Finally, the respondents were questioned.

\subsection{Regression}

The aim of regression analysis is to research the relationship between the dependent variable and indigenous variables based on the 5 percent sense point. If the significance amount is below 0.05 , the null hypotheses are refused and the alternative is approved. Table 1 demonstrates the summary of the regression analysis. 
Table 1

The summary of the regression analysis

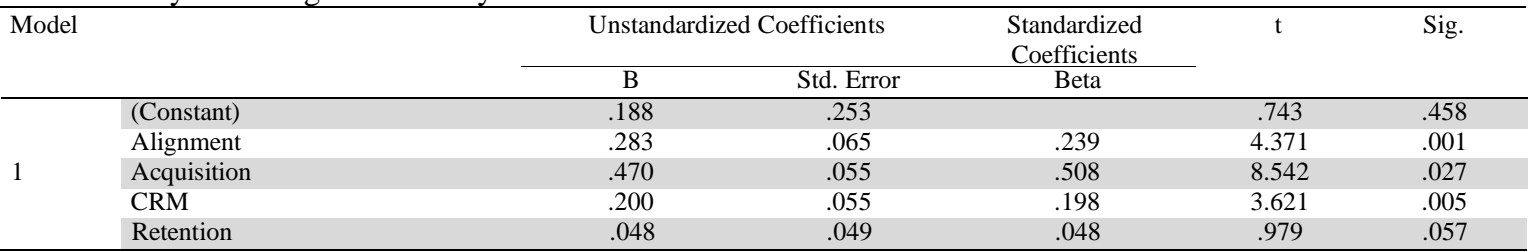

a. Dependent Variable: Recognition $R=0.805$ R-Square $=0.648$ Sdjusted R-Square $=0.640$. Std. Error of the Estimate $=0.666$

When the margin of error is smaller than 5 percent, the regression rule specifies that the alternate hypotheses (H1) are acceptably discarded, as with the zero hypotheses. The following may then be inferred on the basis of the aforementioned analysis:

There are links between corporate alignment and customer satisfaction $(0.001)$

Acquisition is linked to customer fulfillment (0.027)

CRM technology and client satisfaction are interrelated (0.005)

Retention and customer satisfaction (0.057) are related. This is rounded to 0.05 , so the null hypotheses are rejected and the alternative can be accepted.

$\mathrm{Y}=\mathrm{A}+\mathrm{BX} 1+\mathrm{BX} 2+\mathrm{BX} 3+\mathrm{BX} 4$

Satisfaction $=0.458+0.239$ alignment +0.50 acquisition $+0.198 \mathrm{CRM}+0.048$ Retention

This means that:

- $\quad$ For every $1 \%$ increase in alignment, satisfaction is affected by $23.9 \%$

- For every $1 \%$ increase in acquisition, satisfaction is affected by $50 \%$

- For every $1 \%$ increase in CRM, satisfaction is affected by $19.8 \%$

- For every $1 \%$ increase in retention, satisfaction is affected by $4.8 \%$

\subsection{Pearson Correlation}

The Pearson Correlations test is practiced to test whether the relationship among the research variables is positive or negative, based on an indicator called Pearson Coefficient. Table 2 presents the summary of the Pearson correlation.

Table 2

The results of Pearson correlation

\begin{tabular}{|c|c|c|c|c|c|c|}
\hline & & Satisfaction & Acquisition & Technology & Retention & Alignment \\
\hline \multirow{3}{*}{ Satisfaction } & Pearson Correlation & 1 & $.747^{* *}$ & $.631^{* *}$ & $.703^{* *}$ & $.413^{* *}$ \\
\hline & Sig. (2-tailed) & & .000 & .000 & .000 & .000 \\
\hline & $\mathrm{N}$ & 181 & 181 & 181 & 181 & 181 \\
\hline \multirow{3}{*}{ Acquisition } & Pearson Correlation & $.747^{* * *}$ & 1 & $.602^{* *}$ & $.753^{* *}$ & $.544^{* * *}$ \\
\hline & Sig. (2-tailed) & .000 & & .000 & .000 & .000 \\
\hline & $\mathrm{N}$ & 181 & 181 & 181 & 181 & 181 \\
\hline \multirow{3}{*}{ Technology } & Pearson Correlation & $.631^{* * *}$ & $.602^{* *}$ & 1 & $.574^{* *}$ & $.321^{* * *}$ \\
\hline & Sig. (2-tailed) & .000 & .000 & & .000 & .000 \\
\hline & $\mathrm{N}$ & 181 & 181 & 181 & 181 & 181 \\
\hline \multirow{3}{*}{ Retention } & Pearson Correlation & $.703^{* * *}$ & $.753^{* *}$ & $.574^{* *}$ & 1 & $.491^{* * *}$ \\
\hline & Sig. (2-tailed) & .000 & .000 & .000 & & .000 \\
\hline & $\mathrm{N}$ & 181 & 181 & 181 & 181 & 181 \\
\hline \multirow{3}{*}{ Alignment } & Pearson Correlation & $.413^{* *}$ & $.544^{* *}$ & $.321^{* *}$ & $.491^{* * *}$ & 1 \\
\hline & Sig. (2-tailed) & .000 & .000 & .000 & .000 & \\
\hline & $\mathrm{N}$ & 181 & 181 & 181 & 181 & 181 \\
\hline
\end{tabular}

**. Correlation is significant at the 0.01 level (2-tailed).

Based on the above table, the following relationships are highlighted:

- Positive relationship between Acquisition and satisfaction (74.7\%)

- Positive relationship between technology and satisfaction (63.1\%)

- Positive relationship between retention and satisfaction (70.3\%)

- Positive relationship between alignment and satisfaction (41.3\%) 


\section{Summary of Findings}

The research aimed to examine the effect on corporate success in the banking sector through Customer Relationship Management. First, a further review has been made of the consumer retention levels and CRM's effect on customer retention.

The research found that, if the consumer loyalty is quite high, the industry's capacity to keep its clients is directly related to its degree of satisfaction; thus, an analysis is intended to demonstrate that there is a connection between such two variables. The researcher thus concludes that consumer engagement and customer loyalty have a major connection. The maintenance of consumers benefits directly from consumer loyalty.

The key results have demonstrated that CRM system adoption, corporate cohesion, consumer loyalty and retention have a clear connection. The regression study indicates a margin of error of less than 5 per cent and thus supports the alternate conclusion that " CRM deployment programs have a beneficial impact on consumer satisfaction and retention," with the null being dismissed. Both factors appear to have a meaningful interaction.

Moreover, the research findings comply with the CRM literature review in various countries, which resulted in an increase in customer satisfaction, loyalty and retention that helps to improve the bank's productivity performance.

Research findings have also shown that CRM has a large effect on the bank's performance since it is regarded as a means of keeping customers up-to - date on the latest products to ensure and improve its performance.

Results also confirmed that the bank uses a regular communication strategy to maintain new products and services with its customers. It is part of the CRM cycle that attracts clients and improves the bank's corporate profile.

To confirm the aforementioned conclusions, $81 \%$ of respondents have reported that they recognize all of the resources the bank offers. This means that the bank efficiently and quickly delivers the resources to its customers.

\section{Customer dissatisfaction}

Customers talked of losing the time in the banking hall in lines. This was because of the amount of service desks they clarified. In comparison with the number of customers who operate on a daily basis against the number of workers who serve them, the conclusion showed that the number of customers a worker handled on a daily basis was relatively high and therefore delayed. Yet now, consumers are searching for a convenient way to run their companies in quick time and save money. The repetitive phrase that came from our customers was, therefore: "time is energy." Time is time, in reality. In banking, all CRM programming must focus on both the company and the customer's mutual benefit. The organizational outcomes of this analysis are calculated according to the levels of fulfillment and retention of consumers, as described earlier. The survey thus revealed that the branch's performance is related to the strategies of customer relations that translate into customer satisfaction.

\section{Limitations of Study}

In the course of this study, the researcher faced a number of restrictions and obstacles.

The period that the answerers took to complete the questionnaire and get back to me is one of the problems faced and that could not be managed and controlled.

Moreover, a quantitative and non-qualitative methodology is used because the target group is customers only, and therefore there have not been detailed interviews which would have given the bank's and its employees more insight into their CRM impacts.

\section{Recommendations}

In enhancing the operational efficiency of the corporation, the banking sector should realize the value of customer experience management. Efficient customer relations management should also be a reliable instrument for strengthening the customer base. Each element of consumer's needs must also be taken into consideration and therefore maintain customer loyalty. In order to reduce long waits, the branch will increase its servicing counter line and the client should be encouraged to use ATM outlet basis withdrawals. To enhance actual and planned results, the company has first to execute a CRM audit. Most consumers tend to administrations of better quality. Various factors contribute to the improvement of the performance, such as good customer relationships, organization and corporate procedures, human resource capacity building, budget execution, social responsibility, employed liability, profit increase and many others, etc., between the employee and the customer. Implementation of technologies is the fundamental part behind CRM. Software programs and applications should enable the integration of consumer details in a centralized, department-accessible database. Of example, customer 
satisfaction, duration and purchasing cycle data can be broken down. Customer care is a good place to treat consumers. Brand distinction is essential and almost necessary and, above all, it must not be the same as that of the rival. The most effective way to do so is through understanding of and awareness of the customers ' needs. Instead of merely raising money, banks can invest money in technological advances and loyalty programs. Customer satisfaction is an additional benefit to the Company, and funded clients will be paid for games, souvenir delivery and bursaries. The bank's transparency would be increased.

\section{Practical Implications}

This study has shown that CRM management and customer loyalty have a good relationship with retention. In order to satisfy customers, however, CRM should always be updated instead of depending solely on its infrastructure. Additionally, marketing managers must create the current CRM guidelines for the actual use, message and capture of customer data. These guidelines must be linked with pure CRM goals and overseen by the appropriate organization. The definition of CRM organization describes the intervention required to explain actual outcomes. The organization also needs all clients to share their personal details and enable workers perform secure, productive transactions as simply as practicable. Managers will therefore establish strategies and transparent packaging for the development and maintenance of consumer acquisitions. We will also create a compliance regulation framework that helps them to closely track the achievement of consumer group priorities across all touch points and strategies of consumers. One of the main and necessary aspects bank workers will have is ongoing training in customer service to build a positive and long-lasting partnership. The CRM domain is a big concern and it is necessary for successful organizations. The recommendation is that a company should invest a fair sum on customer service strategies to inspire its consumers. Yes, a trustworthy client adds to the bank's strong image.

The benefit of CRM is that it reduces the total operational expenses regardless of the financial background reported by the client in the archive of businesses. The focus on consumer service should be put as consumers can move banks very quickly in today's environment due to intense rivalry and may lose the current bank.

Businesses will then incorporate CRM frameworks and techniques to attract and even make their clients loyal. Consider the following as:

- Build park areas as your parents finish their purchases.

- Sending texts for the wedding,

- Consider early and seasonal gifts, e.g. for Easter and

- Seasons of Advent,

- Create a lifelong confidence bond and offer high-quality facilities that meet your standards.

Quality control is a must in today's administrations such that consumers can be fulfilled with ease, convenience and protection. CRM can also, rather than merely a client experience management program, be deemed an overarching corporate method in order to maintain consumer awareness for all employees. Above all, two-way movement is the consumer data sources. Afterwards, clients will be encouraged to discuss how they are handled by the agency.

\section{Conclusion}

Chapter two of the literature reviewed shows that long-term customer loyalty to an industry depends upon how it is processed (satisfactory). It is thus imperative for the industry to note that the degree of response to customer needs plays an important role in its decision to stay in the industry (retention and growth). In this case, it has been identified that customer complaints are resolved within a short period by the branch and channels have been established to resolve complaints before officials in the branch. The branch employees confirmed that a quick, easy and efficient service offer is their top priority in customer service delivery. Good customer care relationships have contributed to customer satisfaction and therefore it is very important that the company choose to stay and maintain its patronage. Such findings further show that if they are to maintain, attract such consumers and stay loyal, the business will not sacrifice their partnership with customers. In addition, the bank benefits from loyal customers' referrals. The branch's overall strategies have also been matched to what customers consider effective. The interviewing of managers of the strategies in place and the prioritization of these strategies for the support of their business policies made this possible. The overall satisfaction of the customers at the bank halls was positive, with the exception that most clients complained that they waste their time on the queues. Thus, though consumers may not be entirely pleased, they will choose to remain with their branch as they still feel $100 \%$ fulfillment is not feasible, and irrespective of the industry's attempts to appease them, certain consumers can still worry about something. 
Alessandro, A. B. (2009, July). Customer satisfaction and dissatisfaction in retail banking: Exploring the asymmetric impact of attribute performances. Journal of Retailing and Consumer Services, 16(4), 271-280, . Retrieved from https://doi.org/10.1016/j.jretconser.2009.02.002

Ang, L., \& Buttle, F. (2006). Customer retention management processes: A quantitative study. European Journal of Marketing, 40(1), 83-99. Retrieved from https://doi.org/10.1108/03090560610637329

Lawson-Body, A., \& Limayem, M. (2004). The impact of customer relationship management on customer loyalty: The moderating role of web site characteristics. Journal of Computer-Mediated Communication, 9(4), JCMC944.

Becker, J. U., Greve, G., \& Albers, S. (2009). The impact of technological and organizational implementation of CRM on customer acquisition, maintenance, and retention. International Journal of research in Marketing, 26(3), 207-215.

Bligh, P.A. (2004). CRM Unplugged: Releasing CRM's Strategic Value Hoboken New Jersey, USA.

Blery, E., \& Michalakopoulos, M. (2006). Customer relationship management: A case study of a Greek bank. Journal of Financial Services Marketing, 11(2), 116-124.

Coltman, T. (2007, June). Why build a customer relationship management capability? Journal of Strategic Information Systems, 16(3), 301-320. . Retrieved from https://doi.org/10.1016/j.jsis.2007.05.001

DeKay, S. (2009). Are business-oriented social networking web sites useful resources for locating passive jobseekers?

Results of a recent study. Business Communication Quarterly, 72(1), 101-105.

Dimitriadis, S., \& Stevens, E. (2008). Integrated customer relationship management for service activities. Managing Service Quality: An International Journal, 18(5), 496-511. Retrieved from https://doi.org/10.1108/09604520810898857

Dwyer, F. R., \& Tanner, J. F. (2006). Business Marketing: Connecting Strategy, Relationship and Learning, 2nd edn. McGraw - Hill Irwin. McGraw.

Farquhar, J. (2004). Customer retention in retail financial services: an employee perspective. The International Journal of Bank Marketing, 22(2), 86-99.

Ghavami, A., \& Olyaei, A. (2006). The impact of CRM on customer retention,' MSc. thesis, Department of Business Administration and Social Sciences. Lulea University of Technology. doi:LTU-PB-EX--06/02$\mathrm{SE}$

Guo, L., Xiao, J. J., \& Tang, C. (2009). Understanding the psychological process underlying customer satisfaction and retention in a relational service. Journal of Business Research, 62(11), 1152-1159.

Gifford, R. (2002). Making a difference: Some ways environmental psychology has improved the world. In R. Bechtel \& A. Churchman (Eds.) Handbook of environmental psychology (2nd ed.). New York: Wiley.

Greenberg, P. (2004). CRM at the speed of light: Essential customer strategies for the 21st century, 3rd edn. McGraw Hill. Greve, G. \&. (2006). Determinants of performance in customer relationship management Assessing the technology usage- performance link. Proceedings of the 39th Annual Hawaii International Conference on System Sciences (HICSS'06), 10.1109/HICSS.2006.121.

Hair, J. F., Money, A. H., Samouel, P., \& Page, M. (2007). Research methods for business. Education+ Training, 49(4), 336-337.

Herman, R. D., \& Renz, D. O. (2008). Advancing nonprofit organizational effectiveness research and theory: Nine theses. Nonprofit Management and Leadership, 18(4), 399-415.

Juan, L. U., \& Yan, L. U. (2009). Dimensions and influencing factors of customer loyalty in the intermittent service industry. Frontiers of Business Research in China, 3(1), 63-78.

Kandampully, J., \& Hu, H. H. (2007). Do hoteliers need to manage image to retain loyal customers?. International Journal of Contemporary Hospitality Management, 19(6).

Karin, A., \& Venetis, P. N. (2004). Service quality and customer retention: building long-term relationships. European Journal of Marketing, 38(11/12), 1577-1598. Retrieved from https://doi.org/10.1108/03090560410560254

Keramati, A., Mehrabi, H., \& Mousakhani, M. (2008, July). The role of human, organization and technology in building competitive advantage with CRM: The case of iranian internet service industry. In 2008 6th IEEE International Conference on Industrial Informatics (pp. 1279-1284). IEEE.

Keramati, A., Mehrabi, H., \& Mojir, N. (2010). A process-oriented perspective on customer relationship management and organizational performance: An empirical investigation. Industrial Marketing Management, 39(7), 1170-1185.

Levesque, T., \& McDougall, G. H. (1996). Determinants of customer satisfaction in retail banking. International Journal of Bank Marketing, 14(7), 12-20. Retrieved from https://doi.org/10.1108/02652329610151340

McCall, M., \& Voorhees, C. (2010). The drivers of loyalty program success: An organizing framework and research agenda.

Cornell Hospitality Quarterly, 51(1), 35-52.

Mooney, J. G., Gurbaxani, V., \& Kraemer, K. L. (1996). A process oriented framework for assessing the business 
value of information technology. ACM SIGMIS Database: the DATABASE for Advances in Information Systems, $27(2), 68-81$.

Newell, F. (2000). Loyalty.com: Customer Relationship Management in the New Era of Internet Marketing. McGraw-Hill, New York, NY.

Richards, K. A., \& Jones, E. (2008). Customer relationship management: Finding value drivers. Industrial Marketing Management, 37(2), 120-130.

Sundram, S., Venkateswaran, P. S., Jain, V., Yu, Y., Yapanto, L. M., Raisal, I., Gupta, A., \& Regin, R. (2020). The Impact of Knowledge Management on The Performance of Employees: The Case of Small Medium Enterprises. Productivity Management, 25(1S), 554-567.

Setiawan, R., Pio, L., Cavaliere, L., Sankaran, D., Rani, K., Yapanto, L. M., Laskar, N. H., Raisal, I., Christabel, G. J. A., Setiawan, R., Petra, U. K., Airlangga, U., Pio, L., Cavaliere, L., \& Foggia, U. (n.d.). Access to Financial Services and Women Empowerment, through Microfinance eligibility. 1, 841-859.

Verhoef, P. C. (2003). Understanding the effect of customer relationship management efforts on customer retention and customer share development. Journal of Marketing, 67, 30-45. Retrieved from https://doi.org/10.1509/jmkg.67.4.30.18685 
Winer, R. S. (2001). A framework for customer relationship management. California Management Review, 43(4), 89-105.

Retrieved from https://doi.org/10.2307/41166102

Zablah, A. R., Bellenger, D. N., \& Johnston, W. J. (2004). Customer relationship management implementation gaps. Journal of Personal Selling \& Sales Management, 24(4), 279-295.

Zikmund, W. (2000). Business research methods, 6th edn. The Dryden Press.

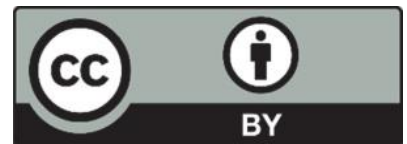

(C) 2021 by the authors; licensee Growing Science, Canada. This is an open access article distributed under the terms and conditions of the Creative Commons Attribution (CC-BY) license (http://creativecommons.org/licenses/by/4.0/). 